\title{
Aids to the drawing of finds
}

\author{
PHILIP KENRICK
}

\begin{abstract}
Philip Kenrick is a graduate of Balliol College, Oxford, now reading for the Diploma in Classical Archaeology. He has spent some time assisting in the preparation of excavation reports in the British School at Rome, and here describes two devices used in the British School to speed up the burdensome task of drawing the finds for publication. We hope, later this year, to publish a note on another such invention for measuring potsherd rim angles on the 'Do-it-yourself' principle, which has reached us from Harvard.
\end{abstract}

The two devices to be described have been in regular use for some time in the British School at Rome, and in view of their proven usefulness I have been encouraged to make them more widely known. The first is an arrangement for drawing pottery profiles by tracing the silhouette cast on a screen by a distant light source-of this I am not the originator-but the second is a form of epidiascope that I designed a few years ago to reproduce small objects at an exact scale of $2: 1$ in such a way that the image may be traced directly on to paper.* Both instruments may be made without difficulty by anyone with a hand for carpentry, the cost of the silhouette screen being negligible, and that of the small-find projector being at present around $f_{5}$. The advantages offered by the use of these instruments will become apparent as their operation is described, and I think that they are both worth serious consideration by anyone faced

*The Grant Projector, which has recently been brought to my notice, operates on the same principle as the instrument that I describe, and perhaps deserves wider publicity amongst archaeologists. It is very much larger than my projector, having a screen about 18 in. $(45 \mathrm{~cm}$.) square, and a variable scale of reproduction. It can be used for the drawing of small objects, though it is designed primarily for the enlargement and reduction of drawings: a disadvantage is that it develops considerable heat around the object. The present price of the basic instrument is f. 288 , and it is manufactured by the Grant Production Co., 4 Rathbone Place, London w.r. with a large quantity of excavated material to be published.

\section{SILHOUETTE SCREEN}

A light is set up at one end of a long room or corridor, and at the other is set a vertical screen of clear glass with a flat platform in front of it; when a pot is stood on the platform, its shadow is cast upon the screen and the profile may be traced on tracing paper attached thereto. The limitation of this method of drawing profiles is that the shadow is, of course, always slightly larger than the object; this is a systematic error which cannot be eliminated, but it can be reduced to an acceptable level if the object is always placed as close against the screen as possible, and if the distance between the light source and the screen is made to be not less than thirty times the height of the object to be drawn. For this reason considerable space is required, as well as semi-darkness, neither of which may always be practicable; the screen described is, however, portable and compact, and the system may be set up anywhere convenient in a few moments.

\section{Construction}

The general design of the screen is shown in FIG. I. None of the dimensions is critical, but I have found $18 \times 12$ in. $(45 \times 30 \mathrm{~cm}$.) to be a useful size for the glass. A rectangular wooden frame is made to this size in $\frac{1}{2}$ in. square ( $12 \mathrm{~mm}$.) 


\section{ANTIQUITY}

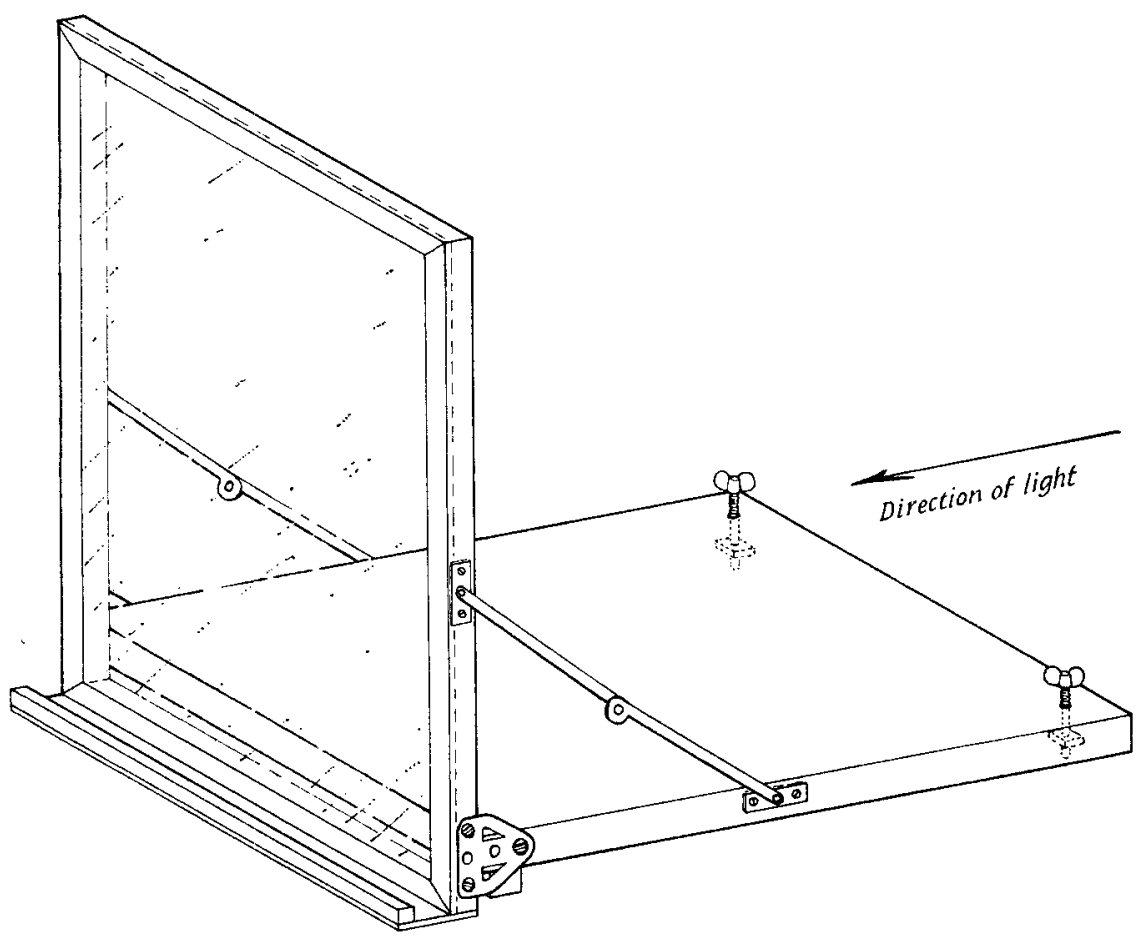

Fig. I. The Silhouette Screen

hard wood, with a narrow tray projecting at the bottom (to hold pencils, masking tape etc.); a sheet of ordinary clear glass is then taped on to it round the edge with a strong adhesive tape, such as 'Sellotape-X'. The platform in front of the screen is made of $\frac{3}{4}$ in. ( $19 \mathrm{~mm}$.) blockboard to the same size as the screen, and the screen is attached to it by hinges in the form of two Meccano 'flat trunnions' (part no. I 26a) as shown in FIG. I; the screen is braced at right angles to the platform by a folding cabinet stay at each side, fitted so that when not in use the whole may be folded flat. Note that when unfolded the screen projects slightly below the platform: this gives a more comfortable position for drawing, and when the screen is set up on a table it hitches over the edge so that one can press against the back without moving it. The platform needs to be adjustable in the angle at which it rests, and to this end a fillet of the same $\frac{1}{2}$ in. square ( $12 \mathrm{~mm}$.) hard wood is nailed to the underside along the edge nearest the screen; at the other end holes are drilled through at either corner to receive butterfly-head bolts, whose nuts are glued into recesses beneath. The surface of the platform must be as flat as possible, and a shiny surface is quite an advantage-at different times I have used a loose sheet of glass, a glazed tile or even a Formica surface glued firmly down. This completes the construction of the instrument, though a hook to keep the screen shut when folded and a carrying handle on one edge are useful adjuncts.

\section{Operation}

A table-lamp or some suitable light source (even a torch will serve) is set up at one end of the room slightly above table height; at the other end is set the screen over the back edge of a table. The screen must now be carefully squared on to the light in order to minimize distortion of the shadow. With a sheet of tracing paper taped to the back of the screen, its angle to the vertical 


\section{AIDS TO THE DRAWING OF FINDS}

is adjusted by screwing up or down the bolts at the front of the platform. If the angle is too low a reflexion will be cast upwards by the shiny surface of the platform, and it should be raised until this reflexion just disappears. The accuracy of alignment may be checked by running a pointed object from the front to the back of the platform: the shadow cast on the screen should not be truncated at any point. This done, the horizontal alignment of the screen must be checked by putting one's eye beside the lamp while an assistant turns the screen sideways until the reflexion of the light appears in the centre of the glass.

When all this has been done the apparatus is ready for use. The sherd to be drawn is placed standing on its rim or base in front of and right up against the screen, and it is turned so that its highest (or truest) profile appears in silhouette. The profile is traced on the paper, and the line of the platform is also marked (this gives the angle at which the pot stands); since only one profile is normally necessary for each pot, a batch of up to a dozen sherds may be traced on the same piece of paper, in which case each profile should be numbered as it is drawn. The pots are then drawn up in the normal way on another sheet, the outlines being copied without further measurement from the profiles taken. With a little practice such batches of sherds may be drawn quickly and accurately, and where complex or irregular shapes are concerned the speed and comparative simplicity of using the silhouette screen strongly recommend the method against more conventional means.

\section{SMALL-FIND PROJECTOR}

As explained at the beginning, this is a form of epidiascope mounted in a vertical plane: the object to be drawn is placed in the bottom under strong lights, and an accurately scaled image with full surface detail is projected on to tracing paper placed over a horizontal glass screen at the top. This means that small finds which have to be drawn at $2: 1$ in order to be published at life-size may be traced accurately and quickly without the tedium of making innumerable measurements with proportional dividers, and in view of the boon that this has proved to be I have modified the instrument since it was first designed to operate alternatively at a scale of $I: I$, so that larger objects may be dealt with in the same way. It is this modified design with two scales of projection that I shall describe here.

\section{Construction}

See FIG. 2 and PL. XXXvi. The dimensions of the instrument are given in the table alongside the drawings; all measurements were originally worked out in inches, and the metric equivalents given have been calculated from them. Dimensions in the horizontal plane have been chosen for convenience and are not critical, but the vertical distances determine the size of the projected image and must therefore be adhered to precisely.

The base of the instrument is of $\frac{3}{4}$ in. ( $19 \mathrm{~mm}$.) blockboard: it is of the same depth as the column, but extends to either side in order to increase the stability of the whole. If the lights used are to belong specifically to the projector (though any sort may be pressed into service) they may conveniently be screwed into the base at either side, and wired to a single switch at the top of the instrument. The main column is supported upon uprights at the four corners, being open below the lens-mounting in order to let light into the object, and enclosed within walls of $\frac{1}{4}$ in. $(6 \mathrm{~mm}$.) plywood above in order to exclude all save that which comes through the lens; the plywood covering the back runs right from top to bottom. At the bottom of the column is a platform of $\frac{3}{8}$ in. $(9 \mathrm{~mm}$.) ply upon which the objects are placed. Since the distance between the lens and the screen determines the scale of projection, focusing must be achieved by moving the object; the platform is therefore mounted on vertical rails. These rails and the runners by which the platform is supported are all constructed from units of Meccano: the details and the part numbers are shown in FIG. $2 d$. The various brackets are screwed into the platform, and the rails are set in holes drilled in the base, and are held by wooden blocks at the top. The platform is raised and lowered by means of a focusing wheel, also of Meccano, at the top of the instrument (FIG. $2 a$ and $b$ ); the 
(a)

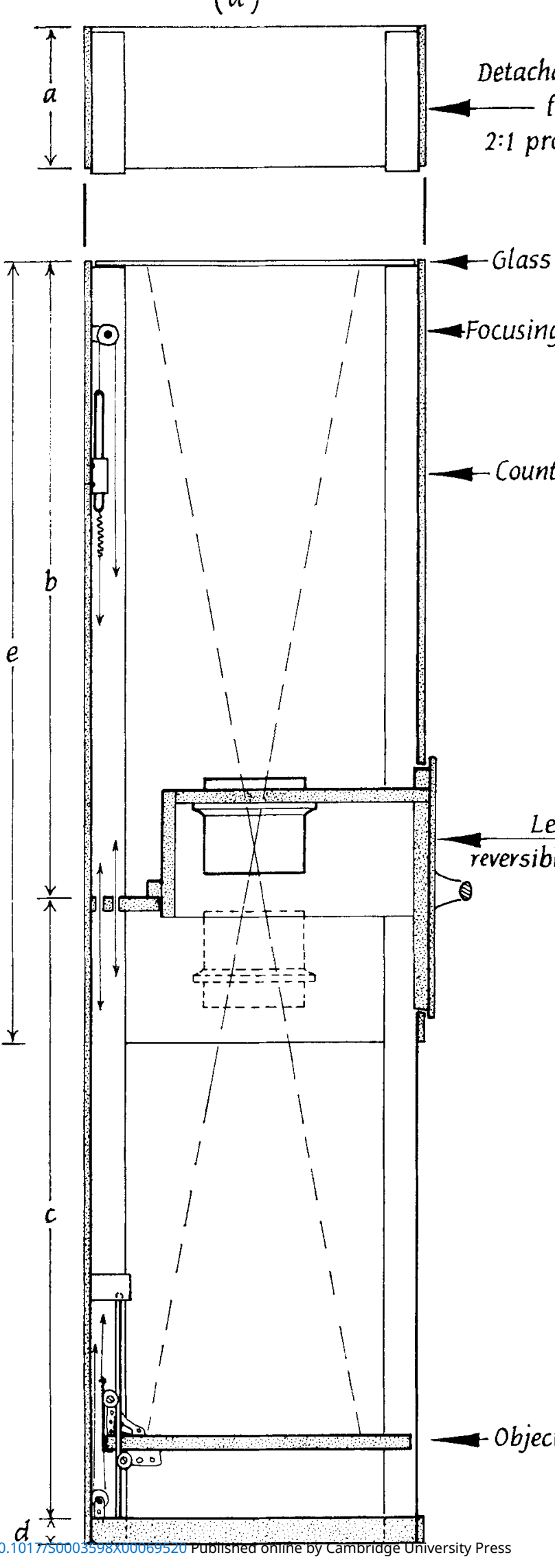

(b)

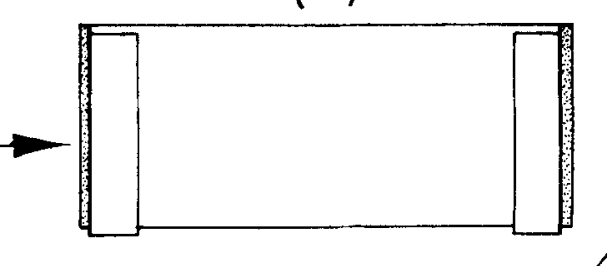

31) Gear wheel (59) Collar

(14) Axle rod

(32) Worm wheel

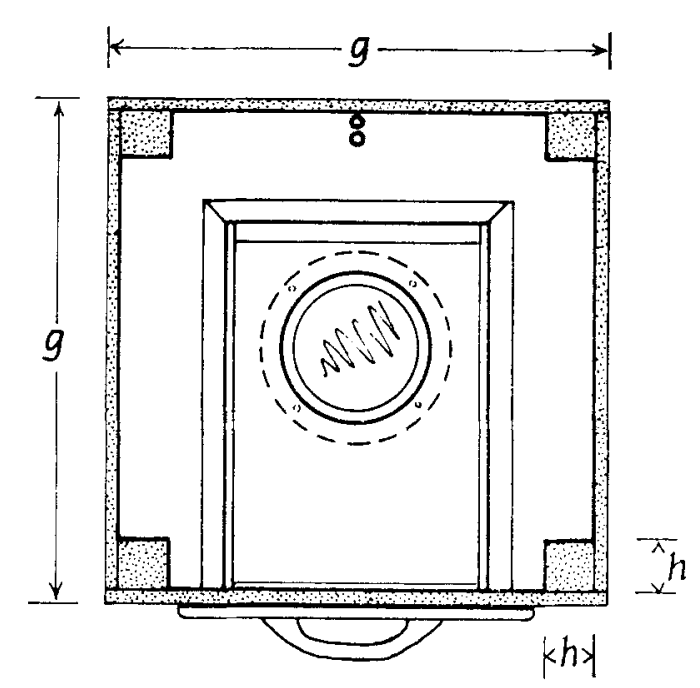

(c)

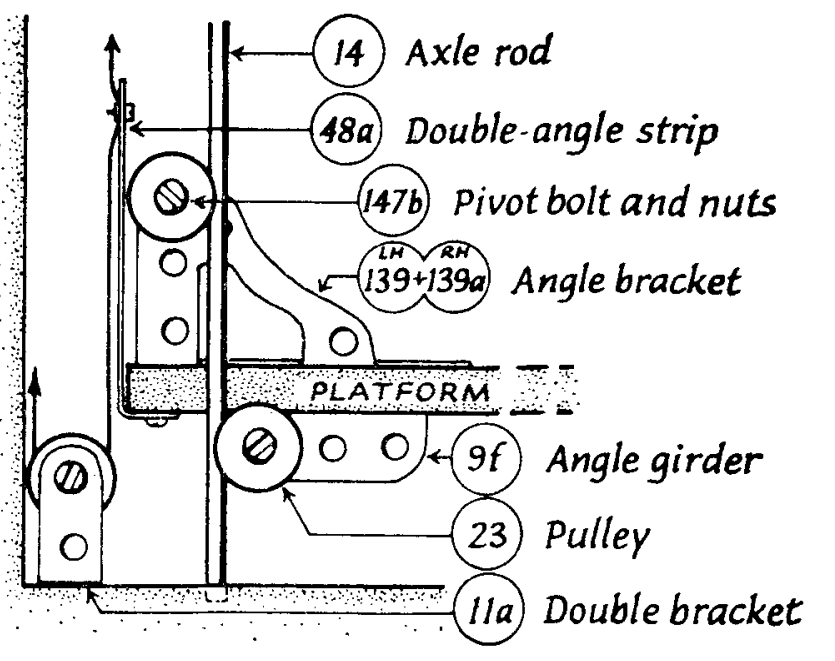

(d)
Horizontal cross-section of the column, looking down on
Enlarged detail of the arrangement of the object platforn (e)

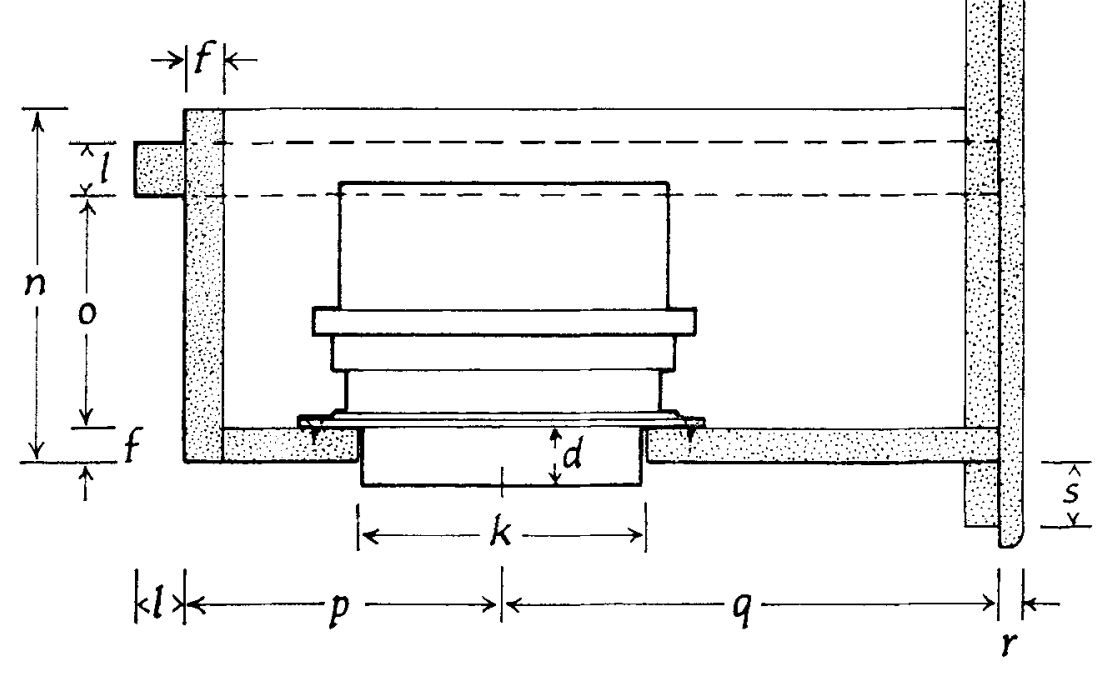

(a) Vertical cross-section from front to back, seen from the left side

(b) Vertical section from side to side, seen from the front
c) Horizontal cross-section of the column, looking down on the lens mounting

Enlarged longitudinal section through lens ' 'drawer'
Enlarged transverse section through lens 'drawer'

Fig. 2. The Small-Find Projector

$\rightarrow \mid f k$
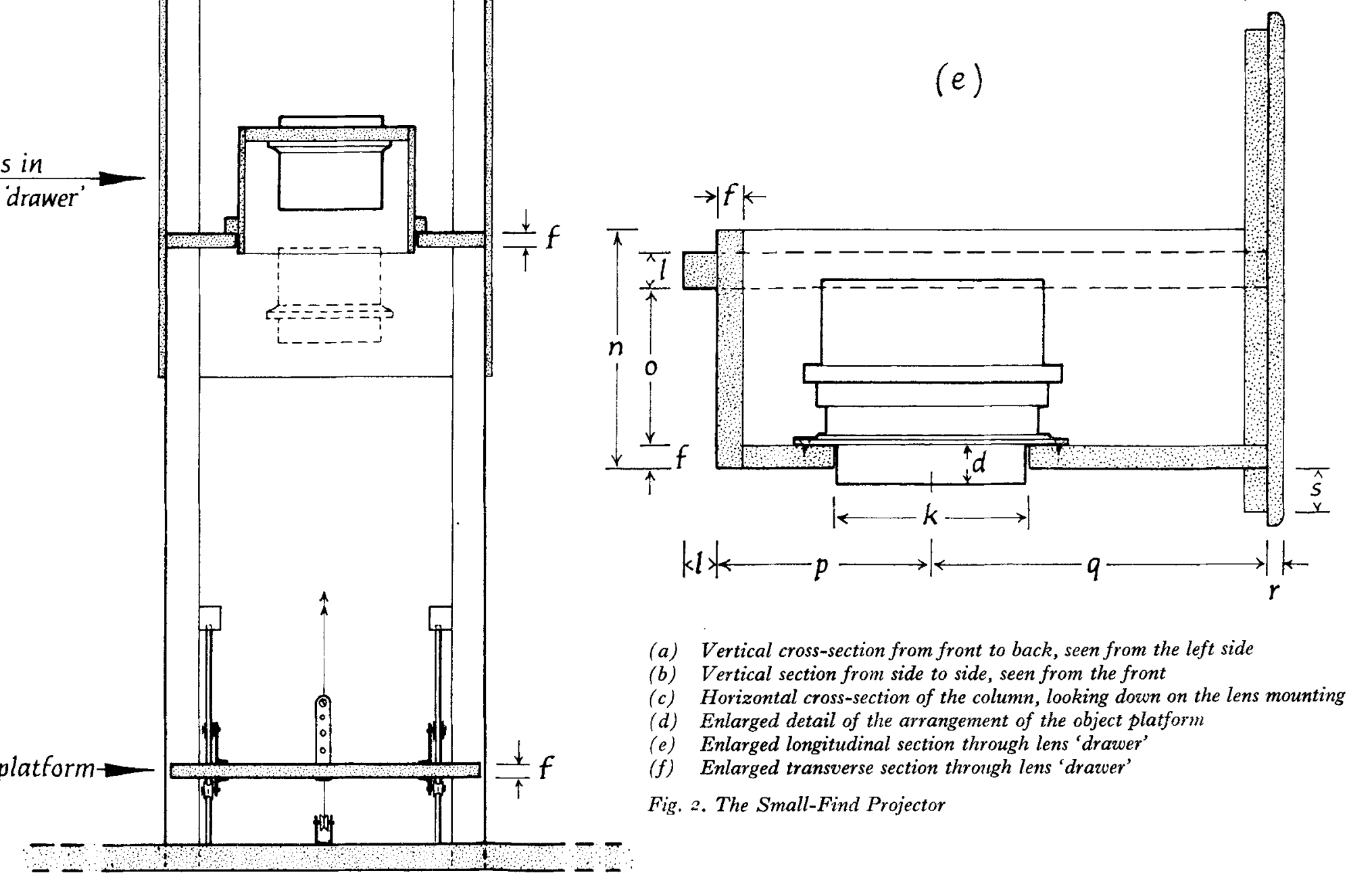

Table of Dimensions

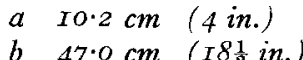

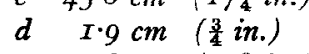

ef $57.8 \mathrm{~cm} \quad\left(22 \frac{3}{3}\right.$ in $)$

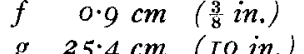

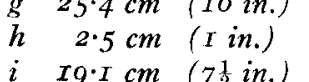

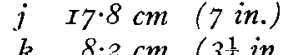

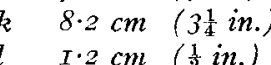

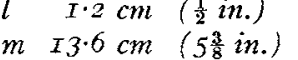

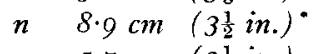

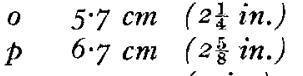

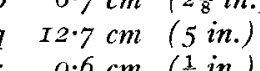

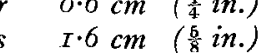

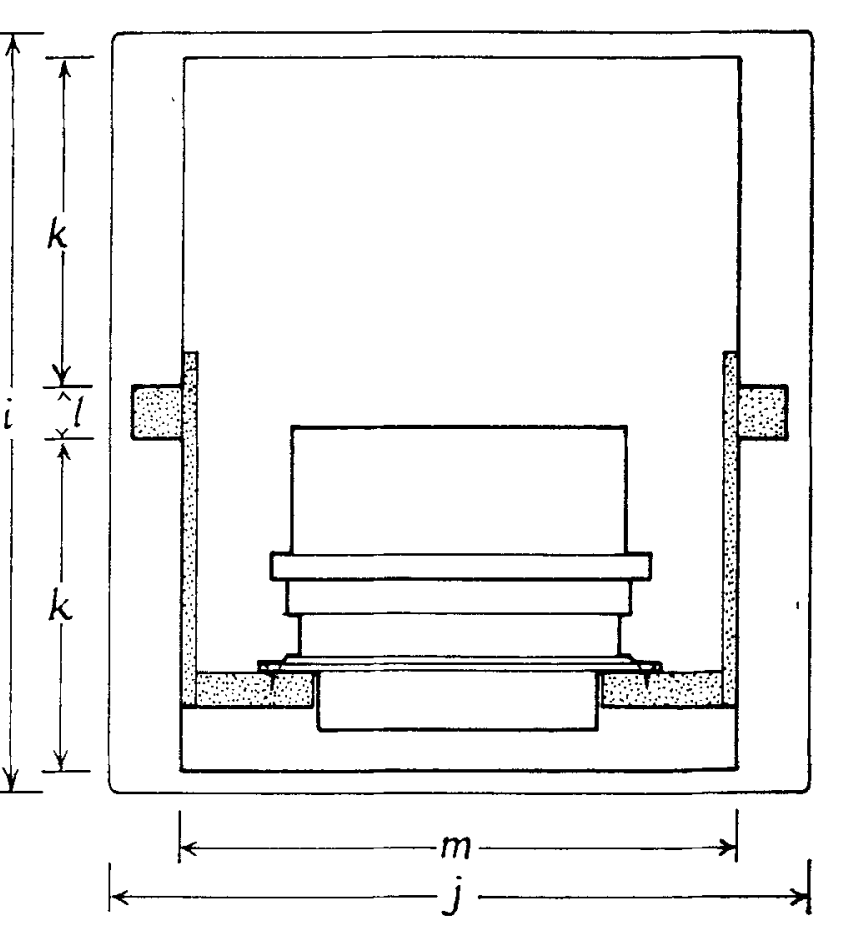

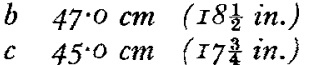




\section{ANTIQUITY}

shaft is passed through one of the uprights at the rear, and is held in place by a collar: the inner end is supported by a small bracket or a block of wood. A double angle strip (part no. 48a) with the upper angle cut off is screwed into the centre of the rear edge of the object platform, and to the top of this is attached a string or nylon line. This line is then led up through a hole drilled in the lens-mounting shelf, twice round the worm wheel at the top and down again behind to a counterweight of approximately $13 \mathrm{oz}$. (370 $\mathrm{grm})$. In order to maintain tension in the line and to increase friction slightly, a spring is hooked on to the bottom of the counterweight, and from this a second line is run down through the lens shelf to the bottom, round a pulley and up again to the platform; it is passed through a hole in the double angle strip, pulled tight and clamped with a nut and bolt (FIG. 2d).

The two scales of projection require the lens to be at different heights, and it is therefore mounted in an asymmetrical 'drawer' (PL. $\mathrm{xxxvib}$ ) which slides into the column from the front and which may be put in either way up. The lens itself is a PENTAC 8 in. $\mathrm{f} / 2.9$ aerial camera lens, available from Messrs Brunnings Ltd., I33 High Holborn, London W.C.I, at 68.50. The lens 'drawer' is made principally of $\frac{3}{8}$ in. $(9 \mathrm{~mm}$.) ply, and is surrounded by a flange of $\frac{1}{2}$ in. ( $12 \mathrm{~mm}$.) square hardwood upon which it rests. The dimensions are shown in FIGS. $2 e$ and $f$. A hole is cut in the bottom of the 'drawer' for the lens, which is held in it by screws passed through its flanged seating. At this point it is important to check that the lens projects exactly $\frac{3}{4}$ in. ( $19 \mathrm{~mm}$.) beneath the flange: it may be necessary to unscrew the lens a little, or to recess slightly the surface of the wood beneath the flange. Within the column, the flange of the drawer rests upon a shelf of $\frac{3}{8}$ in. $(9 \mathrm{~mm}$.) ply, through the rear of which pass the focusing lines (FIG. 2c). The front of the drawer, when pushed in, should be flush with the outside of the column, in which a hole is cut to take it; the addition of a piece of $\frac{1}{4}$ in. $(6 \mathrm{~mm}$.) ply of a slightly larger size, fixed on to the front of the drawer, provides a light seal. It remains to attach a handle.
The screen also has to be placed at different heights for the two scales of projection, and I have found it easiest to make a detachable section which can be clipped on top of the column when the extra height is required. The screen is of clear glass, and rests on the tops of the uprights at the four corners, which are cut off $\frac{1}{8}$ in. $(3 \mathrm{~mm}$.) below the top of the walls in order to make a seating for it. Since the screen is loose and has to be taken off in order to put on the top section, it should be bound round the edges with tape, making a tab at one corner by which it may be lifted out. The detachable section of the column has the same form of seating for the glass on top, but the corners project slightly at the bottom in order to register with the section below. A small overlapping fillet (not shown in the drawings) is also put round the bottom on the inside to form a light seal, and the section is fastened down onto the column by suitcase clips at either side.

When the instrument is completed, the inside of the upper parts and the whole of the lens 'drawer' should be painted with a matt black paint in order to cut down stray light within the system.

\section{Operation}

The sections in FIG. $2 a$ and $b$ show the instrument set to project at $\mathrm{I}: \mathrm{I}-\mathrm{-i}$.e. with the drawer inverted and the lens in the higher position while the screen is in the lower. For 2 : I projection the drawer must be inserted the other way up, and the extra section must be added to the top of the column. The object to be drawn is placed in the centre of the platform at the bottom, and tracing paper is fixed over the screen with masking tape. With the lights on it should be possible to see the image on the paper, but its clarity may be improved by putting a cloth over one's head while drawing. The object is brought into focus by raising the platform with the focusing wheel, and before starting to trace the image one principal dimension should be checked for scale: at $\mathbf{I}: \mathbf{I}$ there is little room for error, but at the larger scale a slight change in focus makes a lot of difference to the size of the image. The object may now be traced, and any fugitive decoration 


\section{AIDS TO THE DRAWING OF FINDS}

in relief may be brought into prominence by altering the angle of the lighting.

By this means any object up to $c .4$ in. (I0 cm.) in length may be drawn at $2: I$ and anything up to 8 in. $(20 \mathrm{~cm}$.) at I : $\mathrm{r}$; the limits are set by the size of the screen, but I think that this is also the widest angle at which the specified lens will work satisfactorily. The depth of field is small, and if the object has a highly irregular surface it may be difficult to get it all in focus at once. The PENTAC lens does, however, have a built-in diaphragm, and a greater depth of field may be obtained by stopping it down, though this will also reduce the brightness of the projected image.

One final word of caution must be added to the description of the Small-Find Projector: the finds drawn by this method will be represented in perspective and not in elevation-but for most purposes the difference between the two at this order of size is unimportant.

\section{NATIONAL MARITIME MUSEUM ASSISTANT KEEPER}

\section{DEPARTMENT OF SHIPS}

A unique opportunity for a graduate to establish himself in a new field of archaeology. The successful candidate will be responsible for a unit being established to further the study of, and set up a gallery on, the archaeology of the boat; to conserve and eventually display the Graveney Boat, the Viking period ship discovered in the Kent marshes last year; and to direct further boat excavations with which the Museum may be concerned. Appointment will be as Assistant Keeper, 1st or 2nd Class, according to age, qualifications and experience.

Candidates (men or women) must have a degree with 1st or 2nd class honours, or post-graduate degree, or equivalent, preferably in archaeology, anthropology or naval architecture. Preference will be given to candidates who have a strong interest in and experience of mensuration, a strong interest in archaeology and the techniques of wooden boat and ship building, and appropriate post-graduate qualifications or experience. A knowledge of German and Scandinavian languages will be an advantage.

SALARY (under review): Assistant Keeper, 1st Class, £2283-£3741. Assistant Keeper, 2nd Class, $£ 1252-2072$. Starting salary may be above the minimum of either scale. Non-contributory pension. Promotion prospects.

AGE: at least 28 for 1 st Class; at least 20 for 2 nd Class.

Write to Civil Service Commission, Alençon Link, Basingstoke, Hants, or telephone BASINGSTOKE 29222 ext. 500 or London 01-839 1696 (24 hour "Ansafone" service), for application form, quoting G/7759. Closing date 27 September 1971. 

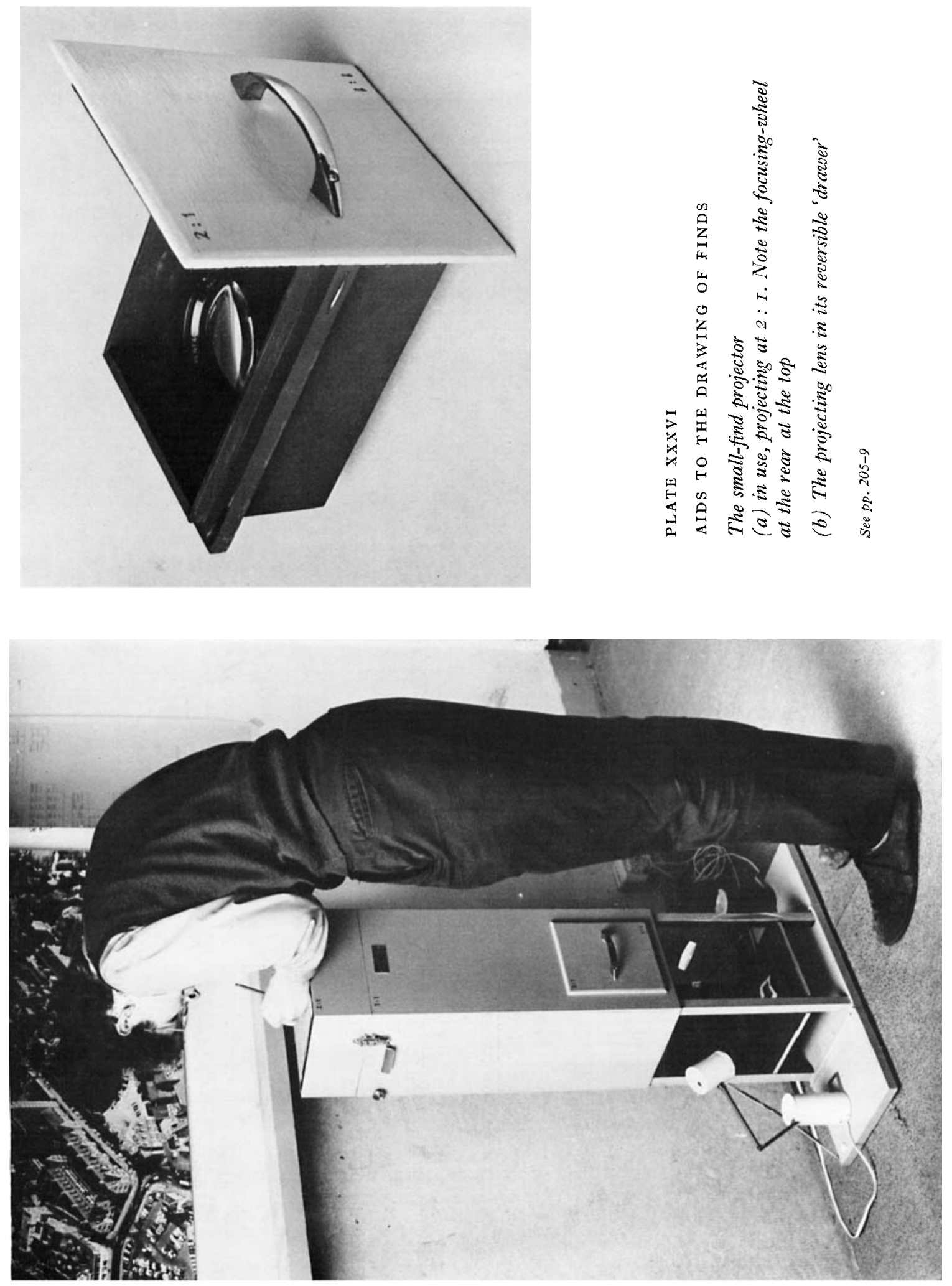